\title{
Phosphate Sequestration From Aqueous Solutions Using A Zeolite in The Zinc Form.
}

Lenin Loayza ( $\sim$ levilope2984@gmail.com )

Universidad Técnica Particular de Loja: Universidad Tecnica Particular de Loja https://orcid.org/00000003-2750-1748

\section{Diana Guaya}

Universidad Tecnica Particular de Loja

\section{Research}

Keywords: phosphate, adsorption, zinc, zeolite, kinetic, isotherm

Posted Date: September 18th, 2020

DOI: https://doi.org/10.21203/rs.3.rs-78047/v1

License: (c) (1) This work is licensed under a Creative Commons Attribution 4.0 International License. Read Full License 


\section{Phosphate sequestration from aqueous solutions using a zeolite in the zinc form.}

Lenin Loayza ${ }^{1}$, Diana Guaya ${ }^{2}$.

1,2 Departament of Chemical and Exact Sciences, Universidad Técnica Particular de Loja. Loja - Ecuador.

Correspondence to: levilope2984@gmail.com

\section{ABSTRACT:}

This work evaluated the ability of a modified zeolite to adsorb phosphates in aqueous solution. The zeolite used for this study was a modified faujasite impregnated with zinc chloride (Z-Zn) on its surface. The experiments were carried out in different stages. Adsorption was performed at different $\mathrm{pH}$ of the solution and the zeolitized material was found to be favorable for phosphate adsorption. The adsorption kinetics occurred after 240 minutes and reach the equilbrium, determining chemisorption reactions with a fit of the particular diffusion model $(D p)$ and pseudo second order, the Langmuir model was best adjusted through the isotherms. The adsorption and desorption process occurs best in the presence of $\mathrm{HCl}$, the formation of residual phosphorous in the fractionation stage evidenced that the highest percentage was bound to metals such as $\mathrm{Fe}$ and $\mathrm{Al}$.

Keywords: phosphate, adsorption, zinc, zeolite, kinetic, isotherm

\section{Highlights:}

- A zinc modified zeolite was used to adsorb phosphates

- Maximun adsorption capacities of $27.5 \mathrm{mg} \mathrm{P} / \mathrm{g}$ was obtained for zinc-modified zeolite.

- Langmuir's model was best fitted at isotherms.

- The psedo second order kinetic model providea good description for the phosphate removal.

- The adsorption kinetics occurred at 240 minutes, determining chemisorption reactions

\section{INTRODUCTION}

Among the important nutrients for the development of biota, phosphorus $(\mathrm{P})$ is considered the limiting factor par excellence of phytoplankton productivity, (Kessler, 2012) in every ecosystem it is the limiting element because, depending on its concentration and presence determines the degree of biological productivity, in this way the concentration of total 
phosphorus (TP) has been traditionally used as an index of water quality and the trophic state of aquatic systems.

Due to the development of various types of detergents at the beginning of the twentieth century gave way to an evolution of the industrial sector for the manufacture of domestic cleaning products, the commercialization of phosphate detergents in various types and at the same time a problem or impact on the environment arose due to unaware of its consequences. Water bodies in the presence of phosphorus and its excess tend to increase biological production, triggering the process called eutrophication, in this way a reduction in the availability of water resources, a decrease in the quality and quantity of water can occur. Another of the main problems associated with the use of phosphorus is found in those fertilizers that contain phosphates, also contributing to eutrophication, although this natural process finds an incentive given by artificial activities, it becomes a problem for bodies of water such as lakes and rivers that are close to agricultural areas where these products are used (Kessler, 2012). The presence of phosphorus in wastewater can occur in the form of ortho phosphates ( $\left.\mathrm{PO} 4{ }^{3-}, \mathrm{HPO}_{4}{ }^{2-}, \mathrm{H}_{2} \mathrm{PO}^{4-}, \mathrm{H}_{3} \mathrm{PO}_{4}\right)$, polyphosphates $\left(\mathrm{P}_{2} \mathrm{O}_{7}\right)$ and as organic phosphorus. The ortho phosphates contribute total phosphorus to the wastewater, which with the polyphosphates and a small proportion of the organic phosphorus constitute all the soluble forms of phosphorus, (Sierra Cruz, 2013).

There is also a problem derived from phosphorus associated with its low availability in the form of phosphate rock and its decreasing purity, the presence of phosphorus in the soil is between 0.01 and $0.10 \%$ organically and varying from according to the soil and climates, (Fósforo \& Agrosistemas, 2006).

The problem of phosphorus was given by its low availability in the form of phosphoric rock and its decreasing purity, we consider that it is an essential biogenic element for living beings, so its activity is limiting in the ecosystem. The relationship between this element is related to organic matter, so the relationship between carbon and phosphorus is between 100 and 200, while the ratio between N / P varies between 10/1 and 10/2, (Fósforo \& Agrosistemas, 2006).

In recent years, the interest in recycling phosphorus has increased; some governments have implemented measures to recover percentages of phosphorus from wastewater, as is the case of Sweden, which has established a recovery of $75 \%$ of the element, (Pastor Alcañiz, 2008). 
The recovered phosphorus could thus be an alternative source of raw materials for the phosphate industry. As an example, one of the main phosphorus producers, Thermphos International (Netherlands) has decided to replace 40 Ton / year of its raw material input P2O5 with recovered phosphorous materials. This company, (Pastor Alcañiz, 2008), is recycling calcium phosphate pellets produced by the Crystalactor process in a treatment plant in the Netherlands.

Some studies evaluated the use of certain materials for the removal of phosphorus from wastewater and the subsequent recovery or desorption of the element, in this case materials such as: zeolites, clays, modified aluminas in the presence of other compounds. With these antecedents, the present work evaluates the applicability of a zeolite modified with zinc for the adsorption of phosphates from aqueous solutions, considering that zeolites have some characteristics, (Erreyes \& Peña, 2019).

The use of zeolites for the adsorption and removal of certain chemical substances is due to their high adsorption capacity, ion exchange, low permeability, physical-chemical stability, and their high surface area, (Fernández Pino, 2011).

Therefore the objectives of this study are: study the influence of $\mathrm{pH}$ and ions concentration on zeolites capacity removal, determine the equilibrium and kinetic sorption parameters, determine and evaluate their perfomance, sorption and desorption, as well as the phosphorus species present in the adsorbent.

\section{MATERIALS AND METHODS}

\subsection{Analytical method}

The concentration of phosphorus $(\mathrm{P})$ was analyzed by the vanadomolubdophosphoric acid colorimetric method (4500-P C), (Guaya, 2012).

\subsection{Zeolitization and modification of clays with $\mathrm{ZnCl} 2$ by impregnation}

The respective samples were made from a faujasite and impregnated with $\mathrm{ZnCl}_{2}$, thus we increase the surface area to obtain an increase in phosphate adsorption capacity .

\subsection{Sample preparation, Faujasite synthesis:}

To get faujasita dissolve $55.5 \mathrm{~g}$ of hydrated nona sodium metasilicate in $222 \mathrm{~g}$ of water. $99 \mathrm{~g}$ of sodium aluminate was added in a controlled manner at room temperature and under stirring for 1 hour until a homogeneous mixture is obtained, taking into account that the mixture becomes transparent and thick. It was left to age at room temperature for 
24 hours. The next step consists of subjecting it to a temperature of $90^{\circ} \mathrm{C}$ for 8 hours and then filtering under vacuum maintaining a $\mathrm{pH}$ of 7-8. It is left to dry at $90{ }^{\circ} \mathrm{C}$ for 24 hours. Then the impregnation with zinc chloride was carried out, for which $30 \mathrm{~g}$ of faujasite was placed in $250 \mathrm{~mL}$ of $0.1 \mathrm{M} \mathrm{ZnCl} 2$ solution.

\subsection{Determination of the point of zero charge (PZC)}

The zero charge point (PZC), in physical chemistry, is a concept related to the phenomenon of adsorption, and that describes the condition when the density of electric charge on a surface is zero. It is generally determined in relation to an electrolyte, and the pzc value was assigned to a specific substrate or colloidal particle. In other words, pzc is usually the $\mathrm{pH}$ value at which a solid immersed in an electrolyte exhibits net zero electrical charge on the surface.

Deionized water and a sodium chloride solution with two different concentrations $(0.01 \mathrm{M}$ and $0.05 \mathrm{M}$ ) are used. $25 \mathrm{~mL}$ of these solutions were placed in centrifuge tubes, the $\mathrm{pH}$ was adjusted to initial values: $3,4,5,6,7,8,9$ and 10 and then 0.1 grams of the Z-Zn (impregnated zeolite with Zinc). It was placed on the magnetic stirrer for 24 hours and the $\mathrm{pH}$ measurement of each of the tubes were taken again and recorded.

\subsection{Effect of $\mathrm{pH}$ on sorption}

A phosphate solution prepared from concentrated sodium phosphate (20mg / L) was used. $25 \mathrm{~mL}$ of this solution was placed in different centrifuge tubes, the $\mathrm{pH}$ was adjusted to initial values: 3, 4, 5, 6, 7, 8, 9 and 10 and 0.1 grams of Z-Zn zeolite impregnated with Zinc. It was placed on the magnetic stirrer for 24 hours. Subsequently, the mixture was filtered and centrifuged to measure the $\mathrm{pH}$ of each of the tubes again and the phosphate concentration was recorded.

\subsection{Assessment of phosphate adsorption capacity.}

- Kinetics of phosphate adsorption:

In this study, the phosphate adsorption mechanism was evaluated using 0.1 grams of $\mathrm{Z}$ $\mathrm{Zn}$ in contact with $250 \mathrm{~mL}$ of a $25 \mathrm{mg} / \mathrm{L}$ phosphate solution at $\mathrm{pH}$ 7.5. This $\mathrm{pH}$ value was used on the basis that conventionally wastewater effluents register this value as part of their physicochemical properties. Aliquots of $5 \mathrm{~mL}$ were taked with time intervals between 30 seconds and 24 hours. After filtered and centrifuged the solutions, the $\mathrm{pH}$ and phosphate concentration, both initial and final, are recorded. 
- Phosphate adsorption isotherms:

The maximum adsorption concentration was determined using solutions of 5.10, 25.50, $100,250,500,1000$ and $2000 \mathrm{mg} / \mathrm{L}$ of phosphate at $\mathrm{pH}$ equal to 7.5. For which $25 \mathrm{~mL}$ of the prepared solutions were placed in centrifuge tubes with $0.1 \mathrm{~g}$ of the $\mathrm{Z}-\mathrm{Zn}$ sample to carry out the adsorption in a period of 24 hours. It was adjusted to a $\mathrm{pH}$ of 7.5 then when filtering the solutions the $\mathrm{pH}$ and the phosphate concentration were recorded, both at the beginning and at the end.

\subsection{Determination of the phosphorus species in the adsorbent (fractionation)}

The fractionation of phosphorus allows us to know and identify the fractions to which the phosphate adsorbed on the solid corresponds.

The method of Hieltjes and Lijklema (Guaya, et.al, 2015) was used for the fractionation of phosphorus in the modified zeolite. 0.25 grams of sample were placed in $25 \mathrm{~mL}$ of phosphate solution with a concentration of $25 \mathrm{mg} / \mathrm{L}$. To determine the fraction of freely bound phosphorus, during the first stage two consecutive extractions were carried out in $20 \mathrm{~mL}$ of $1 \mathrm{M} \mathrm{NH} 4 \mathrm{Cl}$ with a $\mathrm{pH}$ 7. The fraction of metals bound to phosphorus was extracted consecutively on two occasions with $20 \mathrm{~mL}$ of $0.1 \mathrm{M} \mathrm{NaOH}$ followed by extraction in $1 \mathrm{M} \mathrm{NaCl}$. Finally, two consecutive extractions are carried out in $20 \mathrm{~mL}$ of $0.5 \mathrm{M} \mathrm{HCl}$, thus determining the phosphorus bound to zinc and other metals. In the case of residual phosphorus, it was calculated by mass balance between the absorbed phosphorus and the extracted fractions. The tests are done in duplicate and the data is reported.

\subsection{Adsorbent regeneration evaluation}

The purpose of this evaluation is to recover the phosphate already adsorbed, in this way it can be used in a next adsorption-desorption cycle. Phosphate adsorption was carried out at equilibrium using 0.1 grams of modified zeolite in $25 \mathrm{~mL}$ of phosphate solution with a concentration of $20 \mathrm{mg} / \mathrm{L}$ for 24 hours. Subsequently, it was centrifuged and filtered to proceed with the washing and drying of this sample of saturated zeolite whose adsorption capacity is known. $15 \mathrm{~mL}$ of $0.01 \mathrm{M} \mathrm{HCl}(\mathrm{R} 1)$ and $15 \mathrm{~mL}$ of $0.01 \mathrm{M} \mathrm{NaOH}$

$\left(\mathrm{R}^{2}\right)$ were added to the separated solid, it is left under mechanical stirring for a further 24 hours. At the end, for desorption, $25 \mathrm{~mL}$ of the phosphate solution were added to the last 
separated solid and it is subjected to a further 24 hours of mechanical stirring for the subsequent reading of the results.

Previously, for this analytical section, $250 \mathrm{~mL}$ of phosphate solution at a concentration of $20 \mathrm{ppm}, 100 \mathrm{~mL}$ of a $0.1 \mathrm{M} \mathrm{HCl}$ solution and $100 \mathrm{~mL}$ of a $0.1 \mathrm{M} \mathrm{NaOH}$ solution was prepared. After (next day), it is performed the separation of the solid and the liquid by centrifugation and the final concentration is read, also taking $3.5 \mathrm{~mL}$ of the filtered liquid, $0.5 \mathrm{~mL}$ of water and $1 \mathrm{~mL}$ of distilled water in each cell.

\section{RESULTS AND DISCUSSION:}

\subsection{Determination of the zero charge point.}

As can be seen in FIGURE 1, the zero charge point $\left(\mathrm{pH}_{\mathrm{pzc}}\right)$ intervenes with a vital role in the physicochemical reaction, the protons are adsorbed by the material $(\mathrm{Z}-\mathrm{Zn})$ in the contact time, in this way the $\mathrm{pH}$ of the Zinc-modified zeolite ( $\mathrm{Z}-\mathrm{Zn}$ ) charges positively when $\mathrm{pH}<\mathrm{pH}_{\mathrm{pzc}}$, favoring phosphate adsorption, (Guaya, Valderrama, Farran, \& Cortina, 2016). Likewise, the phosphate anion will be repelled by Z-Zn when the surface has a negative charge, in this case $\mathrm{pH}>\mathrm{pH}_{\mathrm{pz}} \mathrm{c}$, for example 9 or 10 . For this case, the $\mathrm{pH}_{\mathrm{pzc}}$ value of $\mathrm{Z}-\mathrm{Zn}$ is 8.5 . Comparing with bibliographic information on other types of adsorbents that have used zinc in their composition, data such as double hydroxides of zinc and aluminum are found in layers where the value of the zero charge point $\mathrm{pH}_{\mathrm{pzc}}$ is 10.05, (Iftekhar, Küçük, Srivastava, Repo, \& Sillanpää, 2018).

TABLE 1 describes some important data on phosphate adsorption of various materials of a similar nature in relation to zeolite impregnated with zinc, among these the best isotherm and kinetic model are described. Some of these materials present results at different temperatures and concentrations, our research takes ambient temperature as a reference. 
FIGURE 1 ZERO CHARGE POINT

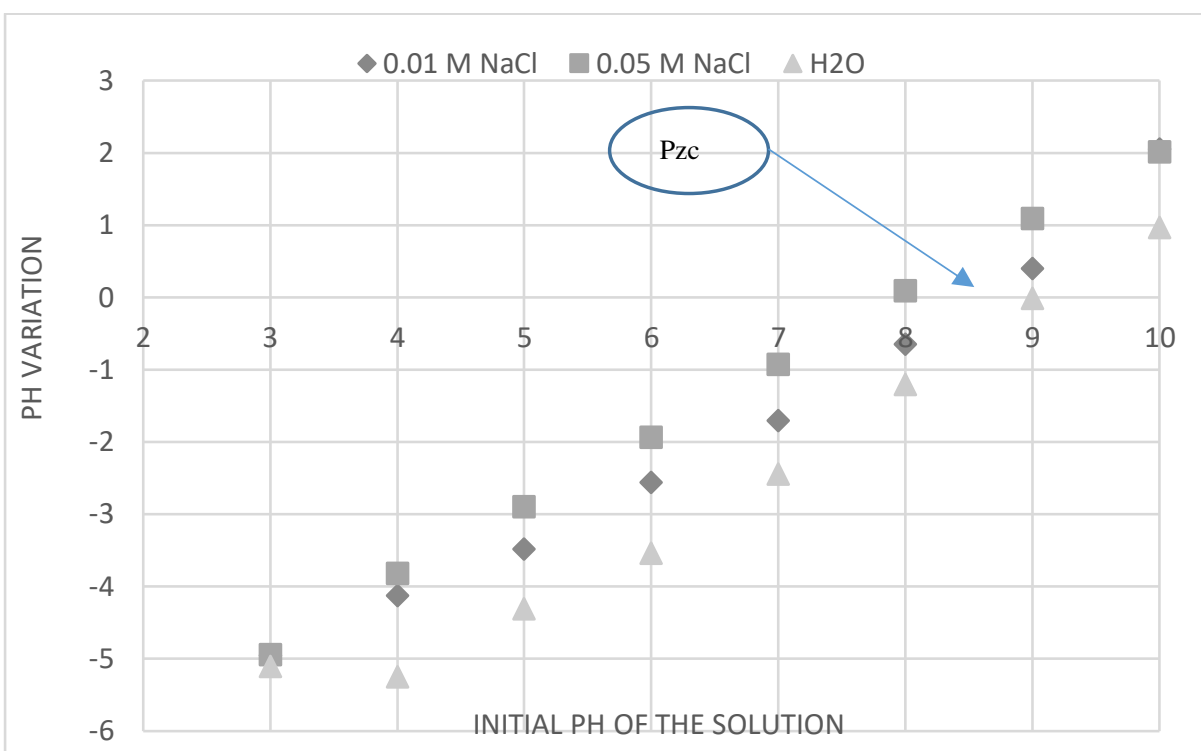


TABLE 1 COMPARISON CHART OF PHOSPHATE ADSORPTION CAPACITY OF DIFFERENT ADSORBENTS

\begin{tabular}{|c|c|c|c|c|c|c|c|c|c|c|c|}
\hline \multirow{2}{*}{ Sorbent } & \multirow{2}{*}{ Description } & \multirow{2}{*}{$\begin{array}{c}\mathbf{T} \\
\left({ }^{\circ} \mathbf{C}\right)\end{array}$} & \multirow{2}{*}{ Fracción } & \multicolumn{3}{|c|}{$\begin{array}{c}\text { Langmuir isotherm } \\
\text { parameters }\end{array}$} & \multicolumn{4}{|c|}{ Kinetic parameters } & \multirow[t]{2}{*}{ Reference } \\
\hline & & & & $K_{L}(\mathrm{mg} / \mathrm{g})$ & $Q_{m}(\mathbf{m g} / g)$ & $\mathbf{R}^{2}$ & Modelo & $\begin{array}{c}\mathrm{K}_{2} \\
(\mathrm{~g} / \mathrm{mg} \cdot \mathrm{min})\end{array}$ & \begin{tabular}{|c|}
$\mathbf{q e}$ \\
$(\mathrm{mg} / \mathrm{g})$
\end{tabular} & $\mathbf{R}^{2}$ & \\
\hline Faujasita & $\begin{array}{c}\mathrm{ZnCl}_{2} \\
\text { modified } \\
\text { faujasite } \\
\end{array}$ & 25 & & 0.0364 & 27.5 & 0.98 & Pseudo second order & 5.87 & 0.41 & 0.98 & This study \\
\hline \multirow[t]{3}{*}{ Zinc Ferrite } & \multirow{3}{*}{$\begin{array}{l}\text { Zinc Ferrite } \\
\text { (ZnFe2O4) by } \\
\text { solvothermal } \\
\text { technique at } \\
\text { different } \\
\text { temperatures. }\end{array}$} & 25 & & 0.5304 & 5.2329 & 0.9895 & \multirow[t]{3}{*}{ Pseudo second order } & 0.0073 & 3.13 & 0.999 & \multirow{3}{*}{$\begin{array}{c}\text { (Gu, Xie, Qi, } \\
\text { Zhao, \& Wu, } \\
\text { 2016) }\end{array}$} \\
\hline & & 35 & & 0.6352 & 5.5726 & 0.9918 & & 0.0077 & 3.36 & 0.9996 & \\
\hline & & 45 & & 0.6233 & 6.2842 & 0.993 & & 0.0078 & 3.52 & 0.9997 & \\
\hline \multirow{8}{*}{ Zinc Ferrite } & \multirow{8}{*}{$\begin{array}{l}\text { Zinc ferrite } \\
\text { with cerium } \\
\text { incorporated } \\
\text { with } \\
\text { temperature } \\
\text { application. }\end{array}$} & & 0 & 0.50 .53 & 5.233 & 0.99 & & & & & \multirow{8}{*}{$\begin{array}{l}\text { (Gu, Xie, Xing, \& } \\
\text { Wu, 2017) }\end{array}$} \\
\hline & & & 0.03 & 0.495 & 9.083 & 0.996 & & & & & \\
\hline & & & 0.12 & 0.538 & 24.01 & 0.994 & & & & & \\
\hline & & & 0.24 & 4.501 & 29.94 & 1 & & & & & \\
\hline & & & 0.48 & 6.599 & 41.632 & 0.999 & & & & & \\
\hline & & 10 & & & & & \multirow{3}{*}{ Pseudo second order } & 0.00058 & 18.99 & 0.9951 & \\
\hline & & 25 & & & & & & 0.00072 & 22.88 & 0.9993 & \\
\hline & & 45 & & & & & & 0.00099 & 25.81 & 0.9984 & \\
\hline \multirow{7}{*}{$\begin{array}{c}\text { Zinc - } \\
\text { aluminium } \\
\text { layered double } \\
\text { hidroxides }\end{array}$} & \multirow{7}{*}{$\begin{array}{c}\text { Zinc- } \\
\text { aluminium } \\
\text { layered doublé } \\
\text { hidroxides } \\
\text { with } \\
\text { temperature } \\
\text { application. }\end{array}$} & 25 & & 240.41 & 2.6 & 0.996 & & & & & \multirow{7}{*}{$\begin{array}{l}\text { (Iftekhar et al., } \\
\text { 2018) }\end{array}$} \\
\hline & & 35 & & 256.73 & 2.59 & 0.997 & & & & & \\
\hline & & 45 & & 414.23 & 2.68 & 0.998 & & & & & \\
\hline & & 55 & & 523.57 & 2.72 & 0.999 & & & & & \\
\hline & & & 0.50 .5 & & & & \multirow{3}{*}{ Pseudo second order } & 4.979 & 0.611 & 1 & \\
\hline & & & 0,75 & & & & & 0.844 & 0.892 & 0.999 & \\
\hline & & & 1 & & & & & 0.365 & 1.245 & 0.999 & \\
\hline
\end{tabular}




\subsection{Effect of $\mathbf{p H}$}

Phosphate adsorption on zinc-impregnated zeolites can occur through chemical and physical interactions, thus adsorption as a function of $\mathrm{pH}$ was represented in FIGURE 2.

The adsorption of phosphate by the modified zeolite occurs better when the solution has $\mathrm{pH} 3$. According to the graph, the values are similar in $\mathrm{pH} 4$ to 6 and $\mathrm{pH} 9$ and 10, (Iftekhar et al., 2018); however, there is a variation in $\mathrm{pH} 7$ and 8 promoting a reduction in phosphate elimination. FIGURE 3 describes the distribution of phosphate species as a function of $\mathrm{pH}$.

In the acidic zone, electrostatic attraction of the phosphate anion is generated with the positive surface charge of the adsorbent (Z-Zn) (equation a), while in the basic zone a repulsive effect of negative charges is generated (equation b). On the surface of the adsorbent ( $\mathrm{Z}-\mathrm{Zn}$ ) another mechanism occurs during adsorption related to the basic zone associated with complexation reactions or formation of phosphate complexes that can be mono and bidentate (equation c), (Di Risio et al., 2013)

(b) $\mathrm{Z}-\mathrm{Zn} \cong \mathrm{MOH}^{+}+\mathrm{H}_{2} \mathrm{PO}^{4-} / \mathrm{HPO}_{4}^{-2} \rightarrow\left(\cong \mathrm{MOH}^{+} \ldots . \mathrm{H}_{2} \mathrm{PO}^{4-} \mathrm{H}_{2} \mathrm{PO}^{4-} / \mathrm{H}_{2} \mathrm{PO}_{4}^{-2}\right)$

(c) $\mathrm{Z}-\mathrm{Zn} \cong \mathrm{MOH}^{+}+\mathrm{H}_{2} \mathrm{PO}^{4-} / \mathrm{H}_{2} \mathrm{PO}_{4}^{-2} \rightarrow \mathrm{Z}-\mathrm{Zn} \cong \mathrm{MH}_{2} \mathrm{PO}^{4-} / \mathrm{H}_{2} \mathrm{PO}_{4}^{-2}+\mathrm{OH}^{-}$

The adsorption process allows reactive chemicals to bond to the surfaces of solids. Small particles, such as clay minerals, have a large specific surface area and thus physically tend to have a high adsorption capacity, (Arbolaez, 2018). In some cases, these physical processes are accompanied by chemical reactions, which cause the precipitation of phosphorus from the soil solution into compounds with different degrees of solubility, known as chemisorption processes, in our case there was no formation of precipitates during the experiment, (Guaya, Valderrama, Farran, Armijos, \& Cortina, 2015).

According to other investigations that evaluate the effect of $\mathrm{pH}$ in the removal of phosphates where materials such as: natural clays, hydrated manganese oxide and bentonites are used, the performance of the Z-Zn material is similar, (Guaya, Valderrama, Farran, \& Cortina, 2017). 
FIGURE 2 EFFECT OF PH ON THE ADSORPTION OF PHOSPHATES BY Z-ZN

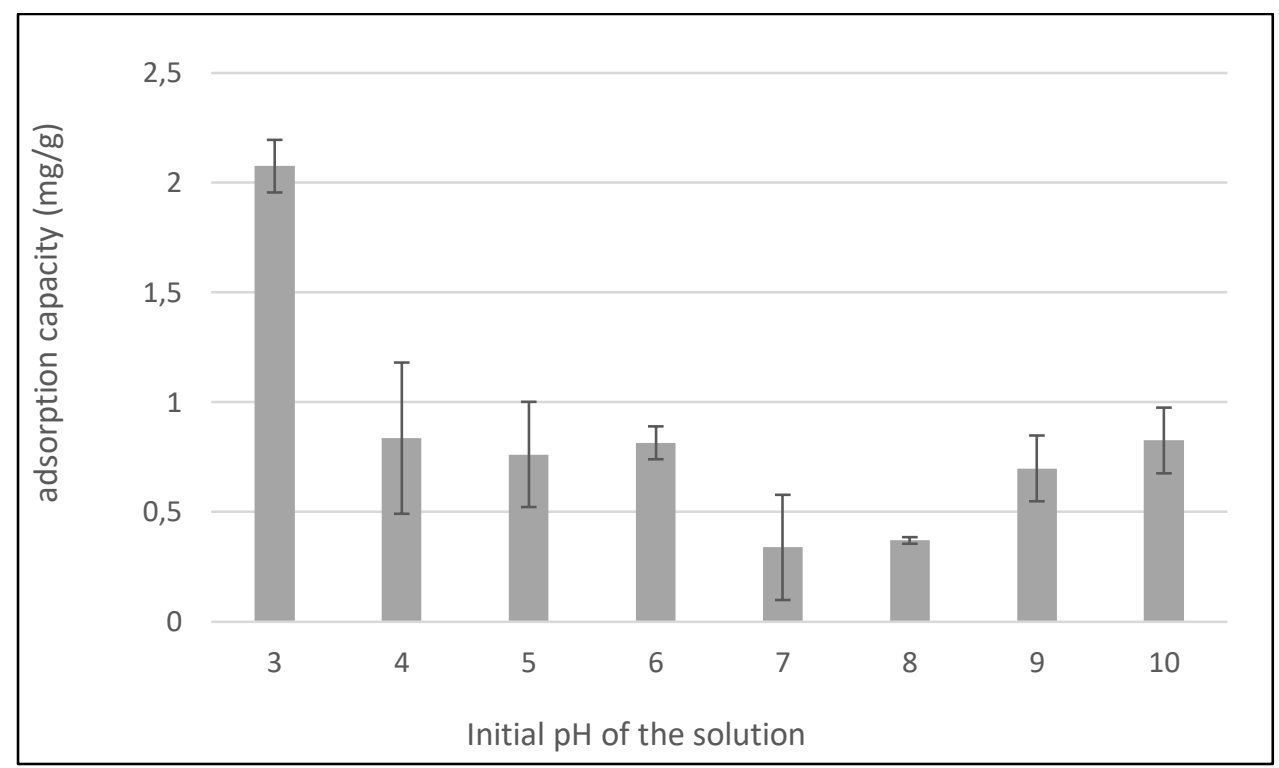

\section{FIGURE 3 SPECIES OF PHOSPHATES AS A FUNCTION OF PH}

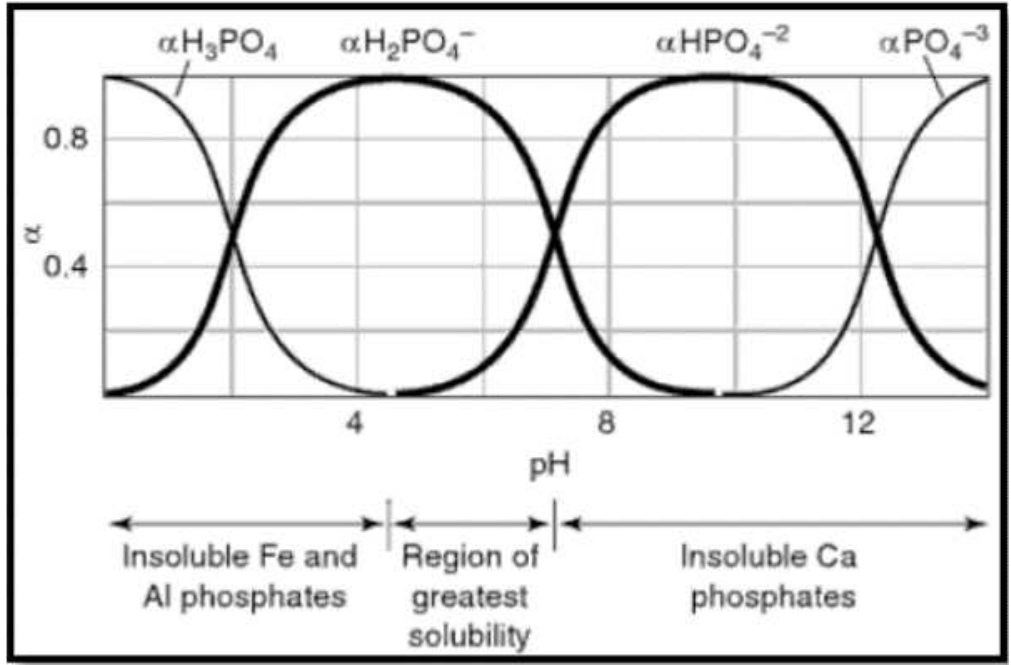

Fuente: (Guaya, 2012)

\subsection{Phosphate isotherms}

The equilibrium uptake for phosphate was calculated using this equation:

$$
\mathrm{q}_{\mathrm{e}}=\left(\mathrm{C}_{\mathrm{o}}-\mathrm{C}_{\mathrm{e}}\right) \times \frac{\mathrm{v}}{\mathrm{w}}
$$

Where $\mathrm{C}_{\mathrm{o}}\left(\mathrm{mgL}^{-1}\right)$ and $\mathrm{C}_{\mathrm{e}}\left(\mathrm{mgL}^{-1}\right)$ represent the initial and equilibirum concentrations. In change, $v(\mathrm{~L})$ is the aqueous solution volumen and $\boldsymbol{w}(\mathrm{g})$ is the mass of the zeolite. The 
phosphate equilibirum soprtion was evaluated according to the Langmuir (a) and Freundlich (b) isotherms.

$$
\begin{aligned}
\text { a) } \frac{C_{\mathrm{e}}}{q_{\mathrm{e}}} & =\frac{1}{K L_{\mathrm{L} \cdot} q_{\mathrm{m}}}+\frac{C_{\mathrm{e}}}{q m} \\
\text { b) } \log q_{\mathrm{e}} & =\lg K_{\mathrm{F}}+\frac{1}{n} \log C_{\mathrm{e}}
\end{aligned}
$$

Where $\mathrm{q}_{\mathrm{m}}(\mathrm{mg} / \mathrm{g})$ is the maximun sorption capacity, $\mathrm{K}_{\mathrm{L}}(\mathrm{L} / \mathrm{mg})$ is the Langmuir sorption equilibrium constant and $\mathrm{K}_{\mathrm{F}}(\mathrm{mg} / \mathrm{g}) /(\mathrm{mg} / \mathrm{L})$ is the Freundlich equilibrium sorption constant, (Guaya et al., 2016).

The data for the equilibrium in phosphate adsorption by the modified zeolite are better described according to the results of our system adjusting to the Langmuir isotherm. The results are shown in TABLE 2, where the value of $\mathrm{R}^{2}$ was 0.98 , it provides the appropriate experimental adsorption data according to this model, so chemisorption is the existing mechanism.

\section{TABLE 2 PARAMETERS OF THE ISOTHERM FOR THE ADSORPTION OF PHOSPHATE IN Z-ZN}

\begin{tabular}{|l|c|c|c|c|c|c|}
\hline \multirow{3}{*}{ Sorbent } & \multicolumn{3}{|c|}{ Langmuir } & \multicolumn{3}{|c|}{ Freundlich } \\
\cline { 2 - 5 } & $\mathbf{Q}_{\mathbf{m}}$ & $\mathbf{K}_{\mathbf{L}}$ & \multirow{2}{*}{$\mathbf{R}^{\mathbf{2}}$} & $\mathbf{K}_{\mathbf{F}}$ & \multirow{2}{*}{$\mathbf{1} \mathbf{n}$} & \multirow{2}{*}{$\mathbf{R}^{\mathbf{2}}$} \\
\cline { 2 - 3 } & $(\mathbf{m g} / \mathbf{g})$ & $(\mathbf{L} / \mathbf{m g})$ & & $(\mathbf{m g} / \mathbf{g})$ & & 0.89 \\
\hline $\mathrm{Z}-\mathrm{Zn}$ & 27.5 & $3.64 \mathrm{E}-02$ & 0.98 & $1.72 \mathrm{E}-04$ & 0.10 & 0.89 \\
\hline
\end{tabular}

Therefore, the results suggest that the availability of affinity sites, are specific and equal, in the zeolite for monolayer and homogeneous sorption, in this case it would be of identical active centers capable of retaining a single sorbate molecule without interaction between these. The amount of available phosphorus is associated with the maximum adsorption value $(\mathrm{Qm})$. The results according to the Langmuir model show a value for Qm of $27.5 \mathrm{mg} / \mathrm{g}$, similar to the experimental results shown in FIGURE 4. According to other studies, carried out under some conditions with temperature variation, there is a good adsorption capacity considering that work has been done with zinc ferrites and with cerium variations where the maximum result obtained has been $41.63 \mathrm{mg} / \mathrm{g}$ but with a fraction of the adsorbent, (Guaya et al., 2017). For the case of 
the adsorption energy coefficient, $\mathrm{K}_{\mathrm{L}}$ of 0.0363 , it is a favorable result, since the condition of the constant $\mathrm{K}_{\mathrm{L}}<1$ is fulfilled, (Guaya et al., 2016).

FIGURE 4 EXPERIMENTAL ISOTHERM OF EQUILIBRIUM FOR PHOSPHATE BY $\mathrm{Z}-\mathrm{ZN}$

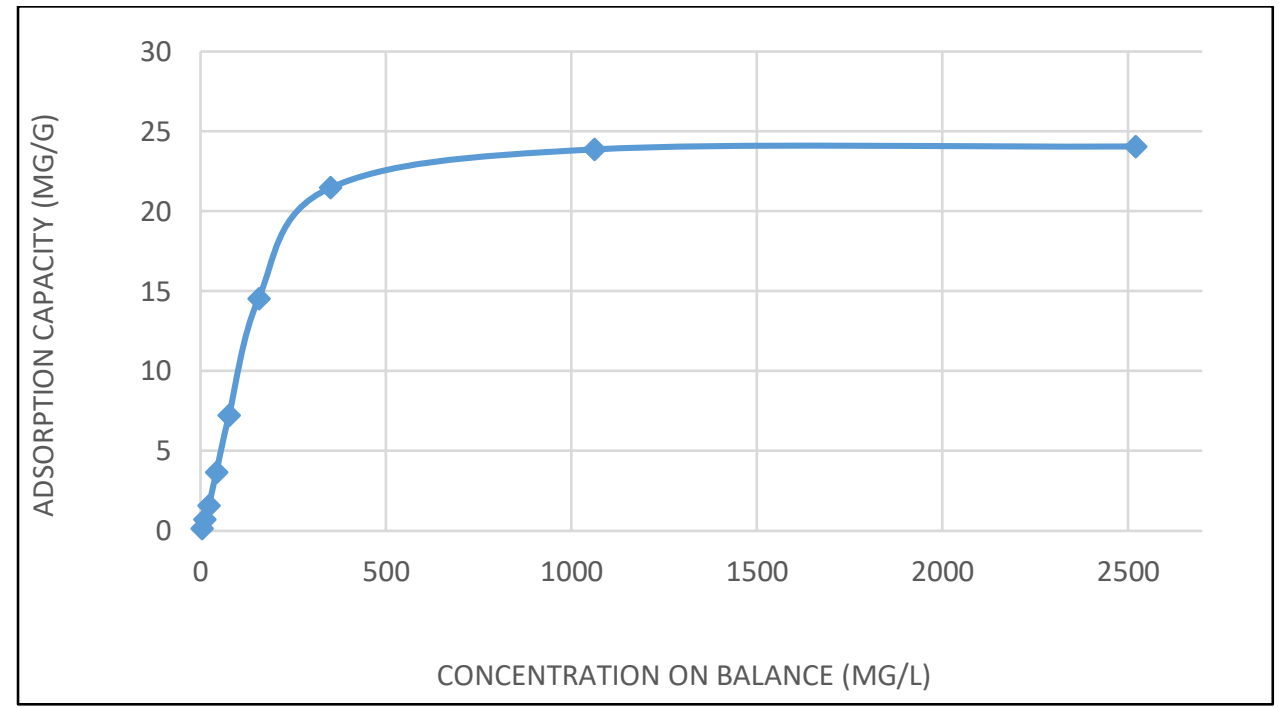

\subsection{Kinetic study}

The kinetic adsorption of the phosphate ion on Z-Zn, as shown in FIGURE 5, describe that equilibrium is reached at $240 \mathrm{~min}$. So the data fit was applied to the pseudo first, second order and particular diffusion models.

FIGURE 5 Z-ZN PHOSPHATE KINETIC ADSORPTION CURVE

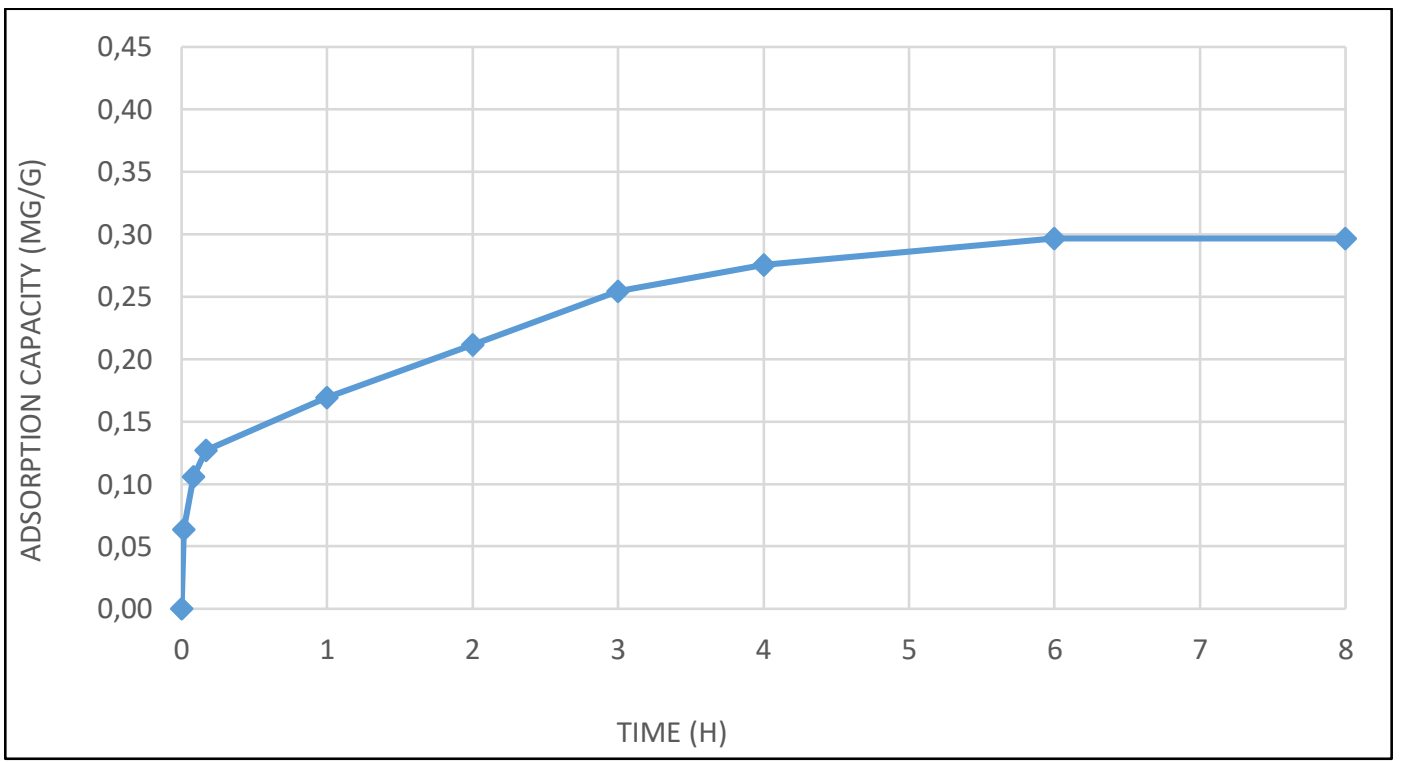


Two adsorption kinetic models, the pseudo first order ant the pseudo second order models, were used to describe our experimental data, (Garces, Coavas, 2012). The pseudo first order model use this equation:

$$
\frac{d q_{t}}{d t}=k_{1}\left(q_{e}-q_{t}\right)
$$

Where $\mathrm{q}_{\mathrm{e}}$ and $\mathrm{q}_{\mathrm{t}}$ are the phosphate adsorbed per unit mass of adsorbente $(\mathrm{mg} / \mathrm{g})$ at equilibrium and the reaction time $\mathrm{t}(\mathrm{min}) . \mathrm{K}_{1}$ is the rate constant $\left(\mathrm{min}^{-1}\right)$, this equation:

$$
\ln \left(\mathrm{q}_{\mathrm{e}}-\mathrm{q}_{\mathrm{t}}\right)=\ln \mathrm{qe}^{-\mathrm{k}}{ }_{1}^{\mathrm{t}}
$$

The pseudo second order model may be represented by:

$$
\frac{\mathrm{dq}}{\mathrm{dt}}=\mathrm{K}_{2} *\left(\mathrm{q}_{\mathrm{e}}-\mathrm{q}_{\mathrm{t}}\right)^{2}
$$

Where $\mathrm{K}_{2}$ is the rate constant (g/(mg.min)), after integration and rearrangement, it may be linearized, (Gu et al., 2016):

$$
\mathrm{q}_{\mathrm{t}}=\frac{\mathrm{q}^{2} \mathrm{e}^{*} \mathrm{~K}_{2} \mathrm{t}}{1+\mathrm{q}_{\mathrm{e}} \mathrm{K}_{2} \mathrm{t}}
$$

The kinetic models of pseudo first order and pseudo second order were used to describe the experimental data. TABLE 3 shows the results obtained. According to the value of $\mathrm{R}^{2}$, the pseudo second order model was better adjusted, in this way it is inferred that the adsorption is a chemisorption process, (Gu et al., 2016). During the process, the particular diffusion model also controlled part of the process. According to the experimental data, an $\mathrm{R}^{2}$ value of 0.93 is obtained, which indicates that the entire sorption process is divided into two linear regions. A first moment in which the phosphate solution surrounds the zeolite particle and a second moment in which the phosphate diffuses towards the nucleus of the adsorbent.

There is information on the speed of the phosphorus reaction processes on solid surfaces, adsorption experiments given in different periods of time show that the phosphorus disappeared from the solution in the first 24 hours is due to rapid adsorption processes which are reversible and occur on the surface of solids, (Gu et al., 2017) .There is a quantity of phosphorus that disappears from the solution in later periods of time through slow processes that are not totally reversible (Rossi, 2011). 
TABLE 3 KINETIC PARAMETERS FOR THE REMOVAL OF PHOSPHATE FROM $\mathrm{Z}-\mathrm{ZN}$

\begin{tabular}{|c|c|c|c|c|c|c|c|c|c|c|}
\hline & \multicolumn{9}{|c|}{ Kinetics models } \\
\cline { 2 - 11 } & \multicolumn{2}{|c|}{$\begin{array}{c}\text { Pseudo first } \\
\text { order }\end{array}$} & \multicolumn{2}{|c|}{ Pseudo second order } & \multicolumn{3}{|c|}{ Intraparticular diffusion } \\
\cline { 2 - 10 } & $\begin{array}{c}\mathrm{Q}_{\mathrm{e}} \\
\mathrm{mg} / \mathrm{g}\end{array}$ & $\begin{array}{c}k_{1} \\
1 / \mathrm{h}\end{array}$ & $\mathrm{R}^{2}$ & $\begin{array}{c}\mathrm{Q}_{\mathrm{e}} \\
\mathrm{mg} / \mathrm{g}\end{array}$ & $\begin{array}{c}k_{2} \\
\mathrm{~g} /(\mathrm{mg} . \mathrm{h})\end{array}$ & $\mathrm{R}^{2}$ & $\begin{array}{c}\mathrm{k}_{i 1} \\
\mathrm{mg} /\left(\mathrm{g} \cdot \mathrm{h}^{1 / 2}\right)\end{array}$ & $\mathrm{R}^{2}$ & $\begin{array}{c}\mathrm{k}_{i 2} \\
\mathrm{mg} /\left(\mathrm{g} \cdot \mathrm{h}^{1 / 2}\right)\end{array}$ & $\mathrm{R}^{2}$ \\
\hline $\mathrm{Z}-\mathrm{Zn}$ & 0.30 & 0.16 & 0.86 & 0.41 & 5.87 & 0.98 & 0.13 & 0.89 & 0.05 & 0.67 \\
\hline
\end{tabular}

\begin{tabular}{|l|l|r|}
\hline Model & $\begin{array}{l}\text { Kinetic } \\
\text { parameters }\end{array}$ & \multicolumn{1}{c|}{$\begin{array}{c}\text { Adsorbent } \\
\text { results }\end{array}$} \\
\hline $\begin{array}{l}\text { HPDF } \\
\text { Film } \\
\text { diffusion }\end{array}$ & $\mathrm{D}_{\mathrm{f}}\left(\mathrm{m}^{2} \cdot \mathrm{h}^{-1}\right)$ & $2.33 \mathrm{E}-08$ \\
\hline $\begin{array}{l}\mathrm{HPDM} \\
\begin{array}{l}\text { Particle } \\
\text { diffusion }\end{array}\end{array}$ & $\mathrm{D}_{\mathrm{p}}\left(\mathrm{m}^{2} \cdot \mathrm{h}^{-1}\right)$ & 0.86 \\
\hline
\end{tabular}

In this model, the species originally in the solution phase must diffuse through the liquid layer surrounding the adsorbent particle, transferring through the solution / particle interface, diffusing throughout most of the adsorbent particle and possibly interacting with a remainder on the surface of the adsorbent.

This particular diffusion pattern crosses the internal structure of the adsorbent pores, for this the structure of the same must be homogeneous porous.

For purposes of comparison with results obtained in other investigations where materials composed of zinc have been used, it has been considered that some analyzes have been with variable temperature, in the case of ferrites impregnated with zinc where the value of qe $=3.13$ at room temperature, (Gu et al., 2016).

In this case, if there is a process controlled by adsorption in the pores, the sorption speed will be directly proportional to the concentration of the solute, (Pinzón-Bedoya \& Villamizar, 2009). 


\subsection{Phosphate adsorption and desorption}

For the process of adsorption and desorption of phosphates, $\mathrm{NaOH}$ and $\mathrm{HCl}$ solutions were used respectively, in FIGURE 6 it is shown.

\section{FIGURE 6 REPRESENTATION OF THE ADSORPTION AND DESORPTION CAPACITY OF PHOSPHATE IN THE PRESENCE OF HCL AND NAOH}

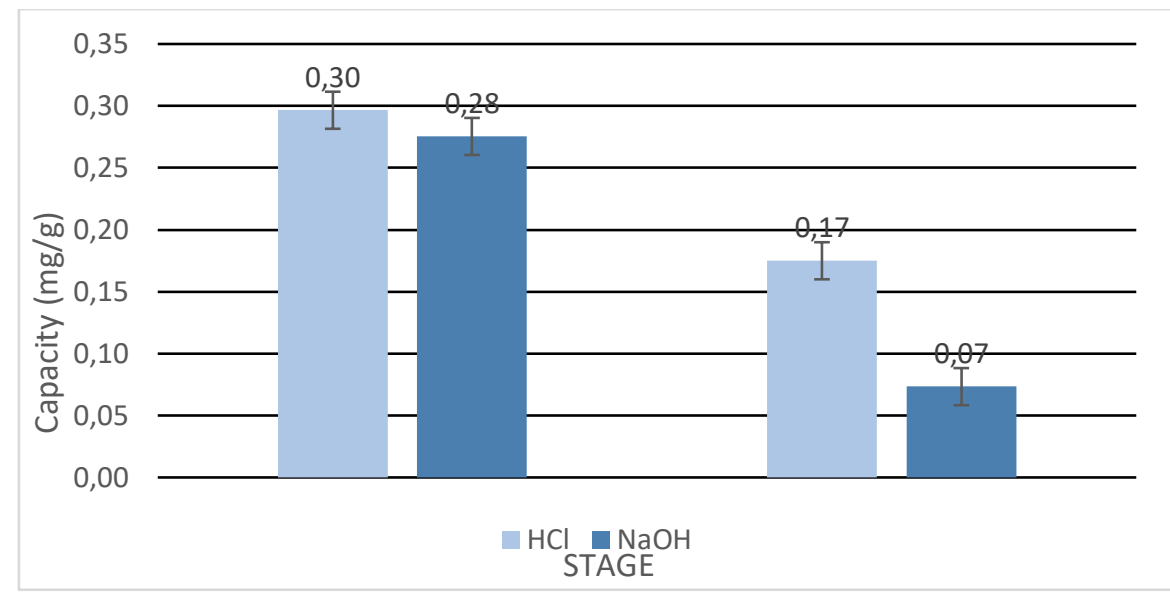

TABLE 4 EFFICIENCY OF THE ADSORTION AND DESORPTION OF PHOSPHATE ON Z-ZN

\begin{tabular}{|c|c|c|}
\cline { 2 - 3 } \multicolumn{1}{c|}{} & HCl & NaOH \\
\hline $\begin{array}{c}\text { Sorption } \\
(\mathrm{mg} / \mathrm{g})\end{array}$ & 0.30 & 0.28 \\
\hline $\begin{array}{c}\text { Desorption } \\
(\mathrm{mg} / \mathrm{g})\end{array}$ & 0.17 & 0.07 \\
\hline
\end{tabular}

TABLE 4 summarizes the phosphate desorption efficiency of the charged zeolites using $\mathrm{NaOH}$ and $\mathrm{HCl}$ in the first sorption-desorption cycle.

These results reveal that the desorption of phosphate was not effective in the presence of $0.1 \mathrm{M}$ $\mathrm{HCl}$ since it was observed that it was possible to recover up to $57 \%$; while in the case of $0.1 \mathrm{M}$ $\mathrm{NaOH}$ a recovery of $25 \%$ was obtained.

The most common way for the desorption of phosphates consists in the addition of a base, usually $\mathrm{NaOH}$, being able to recover sodium phosphate in the solution; However, in this study there was a better adsorption and desorption capacity in the presence of $\mathrm{HCl}$, this may be due to the basicity capacity of the zeolite. Commonly, for strong base anions, the use of high concentration hydrochloric acid is recommended for the desorption of phosphates, (Guaya et al., 2015) 
In some cases the desorption is carried out in columns in the presence of $1 \mathrm{M} \mathrm{HCl}$, in this way the exchangers can be regenerated and reused, also obtaining equations that determine the adsorption capacity of the exchangers, the amount of phosphate adsorbed and the amount recovered, (Huitrón, 2009). The adsorption process in some cases is not reversible since, due to chemisorption, most of the phosphate is bound to the adsorbent. Other studies demonstrate the applicability of other solutions for desorption such as: $\mathrm{NaCl}, \mathrm{KOH}, \mathrm{NaOH}$ in different concentrations, obtaining percentages of $79 \%$ with $\mathrm{NaCl}$ and $93.99 \%$ with $\mathrm{KOH}$, (Guaya et al., 2017).

\subsection{Fractionation of phosphorus species:}

According to the fractionation of phosphorus according to the results presented in TABLE 5, from the $\mathrm{Z}-\mathrm{Zn}$, it was found that the phosphorus with the highest presence is the one bound to the metals $\mathrm{Al}$ and $\mathrm{Zn}$.

TABLE 5 RESULTS OF THE FRACTIONATION OF THE Z-ZN PHOSPHORUS

\begin{tabular}{|c|c|c|c|c|c|c|c|c|c|c|c|}
\hline & & & \multicolumn{3}{|c|}{ P-labil } & \multicolumn{3}{|c|}{ P-metals ( $\mathrm{Zn}) \mathrm{Fe}, \mathrm{Al}$} & \multicolumn{3}{|c|}{$\begin{array}{l}\text { P- alkaline earths } \\
\text { Na, K, Mg, Ca }\end{array}$} \\
\hline \multicolumn{3}{|c|}{ Qad } & \multicolumn{3}{|c|}{$\mathrm{NH}_{4} \mathrm{Cl}$} & \multicolumn{3}{|c|}{$\mathrm{NaOH}$} & \multicolumn{3}{|c|}{$\mathrm{HCl}$} \\
\hline \multicolumn{3}{|c|}{$\mathrm{mg} \mathrm{PO}_{4}^{3-} / \mathrm{g}$} & \multicolumn{3}{|c|}{$(\%)$} & \multicolumn{3}{|c|}{$(\%)$} & \multicolumn{3}{|c|}{$(\%)$} \\
\hline 0.50 .5 & \pm & 0,0 & $25.5 \%$ & \pm & $2.4 \%$ & $56.8 \%$ & \pm & $4.3 \%$ & $17.8 \%$ & \pm & $4.3 \%$ \\
\hline 0.50 .5 & \pm & 0.1 & $29.4 \%$ & \pm & $2.3 \%$ & $52.3 \%$ & \pm & $2.4 \%$ & $18.3 \%$ & \pm & $5.0 \%$ \\
\hline
\end{tabular}

Secondly, the labile phosphor is bound to the adsorbent through electrostatic forces, these results would indicate that the adsorbents have limited reusability. Third, phosphorus is bound to alkaline earths through reactions presumably due to the precipitation of phosphate compounds. Therefore, given its low regeneration and after carrying out a cost-benefit analysis, the possibility of using it as a soil improvement material could be studied. Thus, being a material that could manage the fertilization carried out in the short term on the parameters that determine the availability of the nutrient in the soil such as quantity, capacity and intensity, (Rossi, 2011).

\section{CONCLUSIONS}

The need to recover the phosphate anion from aqueous solutions has influenced the development of this work where the application of a zeolite modified with zinc as an adsorbent is exposed. The study of the zero charge point shows that the adsorbent is favorable for the adsorption of phosphates in real wastewater under the $\mathrm{pH}$ conditions in the range of $7-8$. The 
isotherm better fits the Langmuir model with maximum adsorption capacity of $27.5 \mathrm{mg} / \mathrm{g}$. On the other hand, the adsorption kinetics conforms to the pseudo second order model, which indicates that the process was governed by chemisorption in a time of 240 minutes.

As for the fractionation of phosphorus from $\mathrm{Z}-\mathrm{Zn}$, it was found mostly bound to metals $\mathrm{Zn}, \mathrm{Fe}$ and $\mathrm{Al}$, secondly, labile phosphorus and finally to phosphorus bound to alkaline earths. During the adsorption and desorption cycle in the presence of $\mathrm{HCl}$ it provides a better recovery of the zeolite in view of the basicity of the zeolite. Given that there is a low regeneration of the zeolite, the cost-benefit relationship must be evaluated in the applicability of the large-scale process and thus obtain a concentrate that can be use in soil improvement.

\section{ACKNOWLEDGEMENTS}

L.V Loayza Peñaranda is grateful to UTPL from Ecuador for the support provided to carry out this research work, especially to $\mathrm{PhD}$ Diana Guaya.

\section{AUTHOR'S CONTRIBUTIONS}

Diana Guaya planned, supervised and conducted the experiments and project. Lenin Loayza performed the experiments, interpreted results, conclusions, and prepared the manuscript.

\section{FUNDING}

This work was carried out with own funds.

\section{AVAILABILITY OF DATA AND MATERIALS}

The data used to support the findings of this study are available from the corresponding author upon request.

\section{COMPETING INTERESTS}

The authors declare that they have no competing interests.

\section{AUTHOR DETAILS}

1. Departament of Chemical and Exact Sciences, Universidad Técnica Particular de Loja. Loja - Ecuador.

2. Departament of Chemical and Exact Sciences, Universidad Técnica Particular de Loja. Loja - Ecuador. 


\section{REFERENCES}

Arbolaez, D. M. (2018). Behavior of the quality of the stored water considering the use of Zeolite modified with Zinc in the manufacture of the internal covering mortar in concrete tanks. Hydraulic Engineering Department. Universidad " Martha Abreu de las Villas".

C. Lacasta, R. Meco (*), M. Benítez (**), Phosphorus, E. L., \& Agrosystems, E. N. L. O. S. (2006). Phosphorus in cereal agrosystems. 1-10.

Carbonel, D. (2018). Cadmium, Copper and Lead adsorption into Natural and Modified Bentonite, Kaolin and Zeolite: A Review of Operating Parameters, Isotherms and Kinetics. Engineering, 23(3). https://doi.org/10.14483/23448393.13418

Castellar-Ortega, G., Mendoza Colina, E. D. J., Angulo Mercado, E. R., Jaramillo Colpas, J. E., Paula Pereira, Z. A., \& Rosso Bravo, M. C. (2019). Equilibrium, kinetics and thermodynamics of the adsorption of the dye DB-86 on activated carbon from the cassava shell. Magazine MVZ Córdoba, 14(26), 7231-7238. https://doi.org/10.21897/rmvz.1700

Choque-Quispe, D., Ligarda-Samanez, C. A., Ramos-Pacheco, B. S., Taipe-Pardo, F., PeraltaGuevara, D. E., Solano Reynoso, A. M., ... Solano Reynoso, A. M. (2018). Evaluation of sorption isotherms of grains and flour of amaranth (Amaranthus caudatus). Magazine ION, 31(2), 67-81. https://doi.org/10.18273/revion.v31n2-2018005

Erreyes, Guaya. (2019). Use of natural clays for the recovery of phosphates from aqueous solutions.Universidad Técnica Particular de Loja. Department of Chemistry and Exact Sciences.

Espósito, M. E., Blanco, M. del C., Sequeira, M. E., Paoloni, J. D., Fernández, S. N., Amiotti, N. M., \& Díaz, S. L. (2016). Natural pollution (As, F) and eutrofication (N, P) in the basin of El Divisorio stream, Argentina. Phyton, 85, 51-62.

Fernández Pino, F. (2011). Adsorption System. Retrieved from http://bibing.us.es/proyectos/abreproy/4986/fichero/indice.pdf

Garces, Coavas (2012). Evaluation of the adsorption capacity in the orange peel (citrus sinensis) modified with chitosan for the removal of $\mathrm{Cr}$ (vi) in wastewater. Universidad de Cartagena, Faculty of Engineering, Program of chemical engineering Cartagena de Indias.

Gu, W., Xie, Q., Qi, C., Zhao, L., \& Wu, D. (2016). Phosphate removal using zinc ferrite synthesized through a facile solvothermal technique. Powder Technology, 301, 723-729. https://doi.org/10.1016/j.powtec.2016.07.015

Gu, W., Xie, Q., Xing, M., \& Wu, D. (2017). Enhanced adsorption of phosphate onto zinc ferrite by incorporating cerium. Chemical Engineering Research and Design, 117, 706714. https://doi.org/10.1016/j.cherd.2016.11.026.

Guaya, D. (2012). Experimental evaluation of phosphate removal and recovery from urban wastewater. 77. Universidad Técnica Particular de Loja. Department of Chemistry and Exact Sciences.

Guaya, D., Valderrama, C., Farran, A., Armijos, C., \& Cortina, J. L. (2015). Simultaneous phosphate and ammonium removal from aqueous solution by a hydrated aluminum oxide modified natural zeolite. Chemical Engineering Journal, 271, 204-213. 
https://doi.org/10.1016/j.cej.2015.03.003

Guaya, D., Valderrama, C., Farran, A., \& Cortina, J. L. (2016). Modification of a natural zeolite with $\mathrm{Fe}$ (III) for simultaneous phosphate and ammonium removal from aqueous solutions. Journal of Chemical Technology and Biotechnology, 91(6), 1737-1746. https://doi.org/10.1002/jctb.4763

Guaya, D., Valderrama, C., Farran, A., \& Cortina, J. L. (2017). Simultaneous nutrients (N,P) removal by using a hybrid inorganic sorbent impregnated with hydrated manganese oxide. Journal of Environmental Chemical Engineering, 5(2), 1516-1525. https://doi.org/10.1016/j.jece.2017.02.030

Guaya, D., Valderrama, C., Farran, A., (2017). Valorisation of N and P from waste water using natural reactive hybrid sorbents: Nutrients $(\mathrm{N}, \mathrm{P}, \mathrm{K})$ release evaluation in amenden soils by dinamic experiments.

Iftekhar, S., Küçük, M. E., Srivastava, V., Repo, E., \& Sillanpää, M. (2018). Application of zinc-aluminium layered double hydroxides for adsorptive removal of phosphate and sulfate: Equilibrium, kinetic and thermodynamic. Chemosphere, 209, 470-479. https://doi.org/10.1016/j.chemosphere.2018.06.115.

Lu, J., Liu, H., Liu, R., Zhao, X., Sun, L., y Qu, J., (2013). Adsorptive removal of phosphate by a nanostrtructured $\mathrm{Fe}-\mathrm{Al}$ - Mn trimetal oxide adsorbent.Powder Techonolgy, 233, 246 - 254. https//doi.org/10.1016/j.powtec.2010.08.024.

Kessler, R. (2012). The phosphorus paradox. Environmental health news. Public Health of Mexico, 54(2), 178-187. https://doi.org/10.1590/s0036-36342011000600010

Molinos-Senante, M., Sala-Garrido, R., \& Hernández-Sancho, F. (2010). Viability study of the recovery process of phosphorus contained in wastewater: an economic approach. Rect@, $179-195$.

Pastor Alcañiz, L. (2008). Study of the precipitation and recovery of phosphorus present in wastewater in the form of struvite. (MgNH4PO4.6H2O). 295.

Pinzón-Bedoya, M. L., \& Villamizar, L. E. V. (2009). Modeling of bioadsorption kinetics of cr (iii) using orange peel. DYNA (Colombia), 76(160), 95-106.

Ramos, D. C. (2018). Cadmium , Copper and Lead Adsorption on Natural and Modified Bentonite, Kaolin and Zeolite : A Review of Process Parameters, Isotherms and Kinetics in y Zeolita Naturales y Modificadas : Una Revisi ' on de los Par ' etica. 252-273.

Rojano, G. (2020). "Synthesis and characterization of mineral adsorbents of Fe, Mn and Al for the removal of selenium in the tailings water" Sciences and Technology of the water. Mexican Institute of Water Technology.

Rossi, M. M. S. (2011). Adsorption and desorption of phosphorus in soils of the central area of the Pampean region, Universidad de Córdova.

Sierra Cruz, M. (2013). Vanadium: the king of versatility. MoleQla: Chemistry Journal of Pablo de Olavide University (9), 69-72. Retrieved from http://dialnet.unirioja.es/servlet/extart?codigo $=4178674$. 
Figures

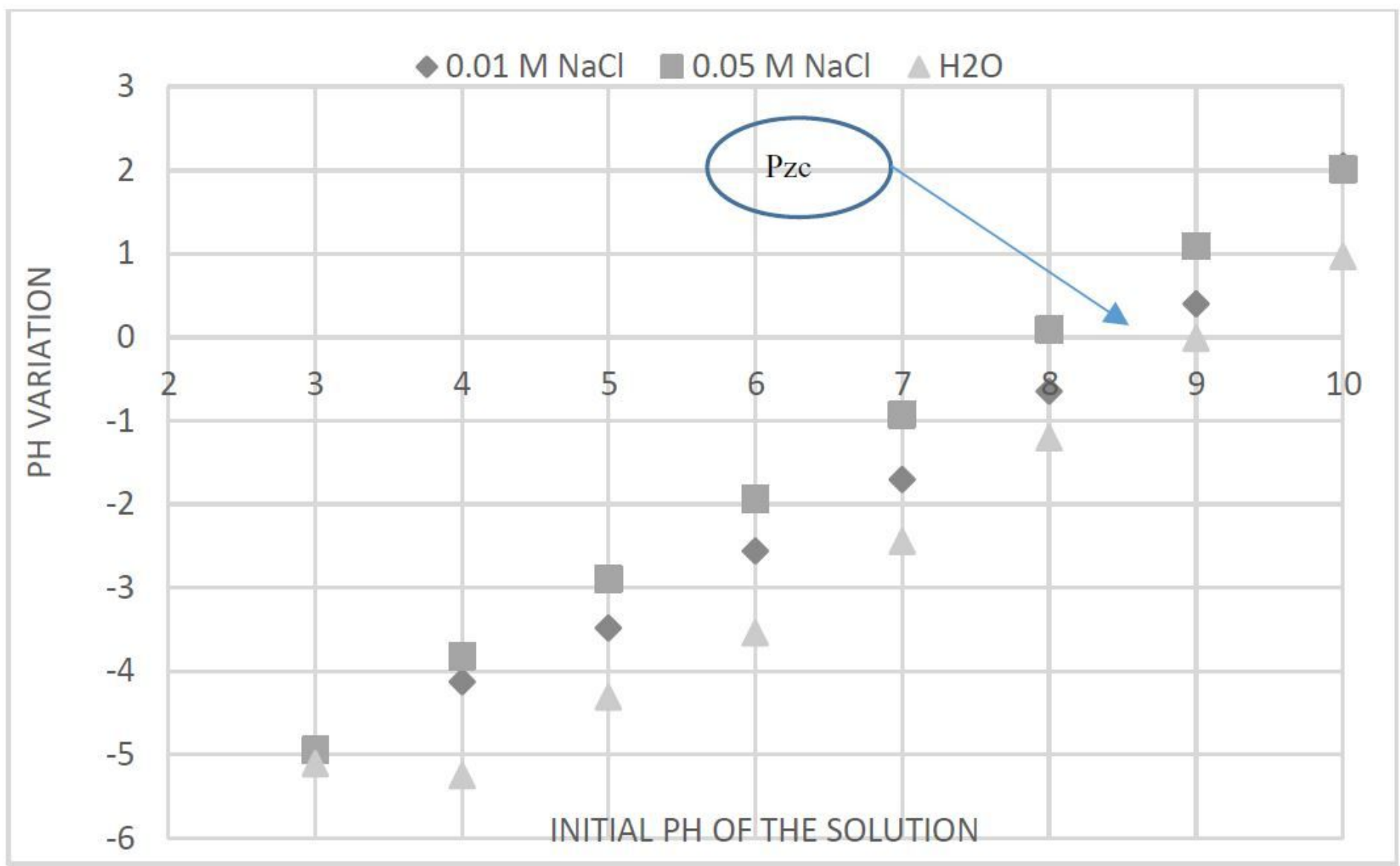

Figure 1

Zero Charge Point 


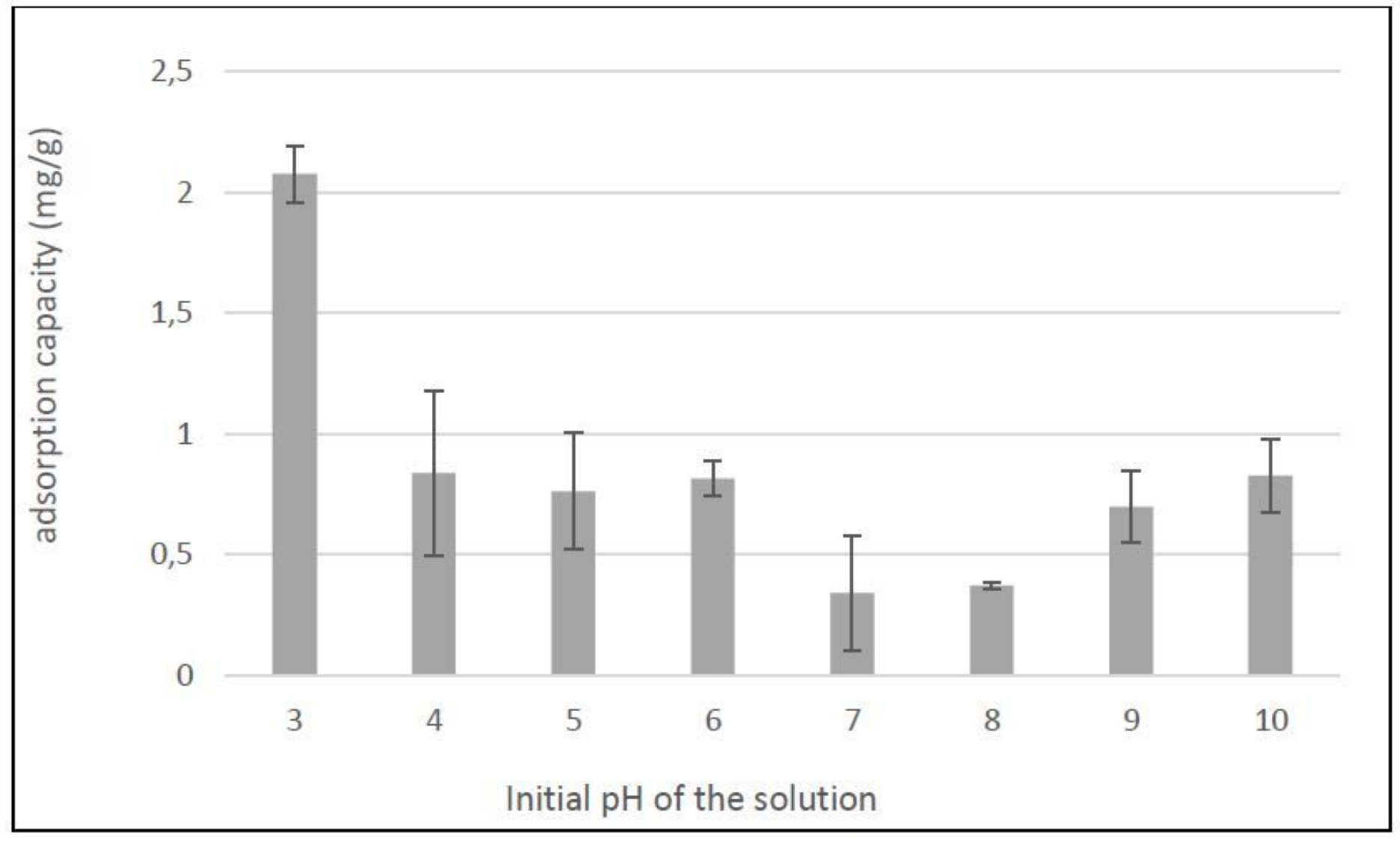

Figure 2

Effect of PH on the Adsorption of Phosphates by Z-Zn 


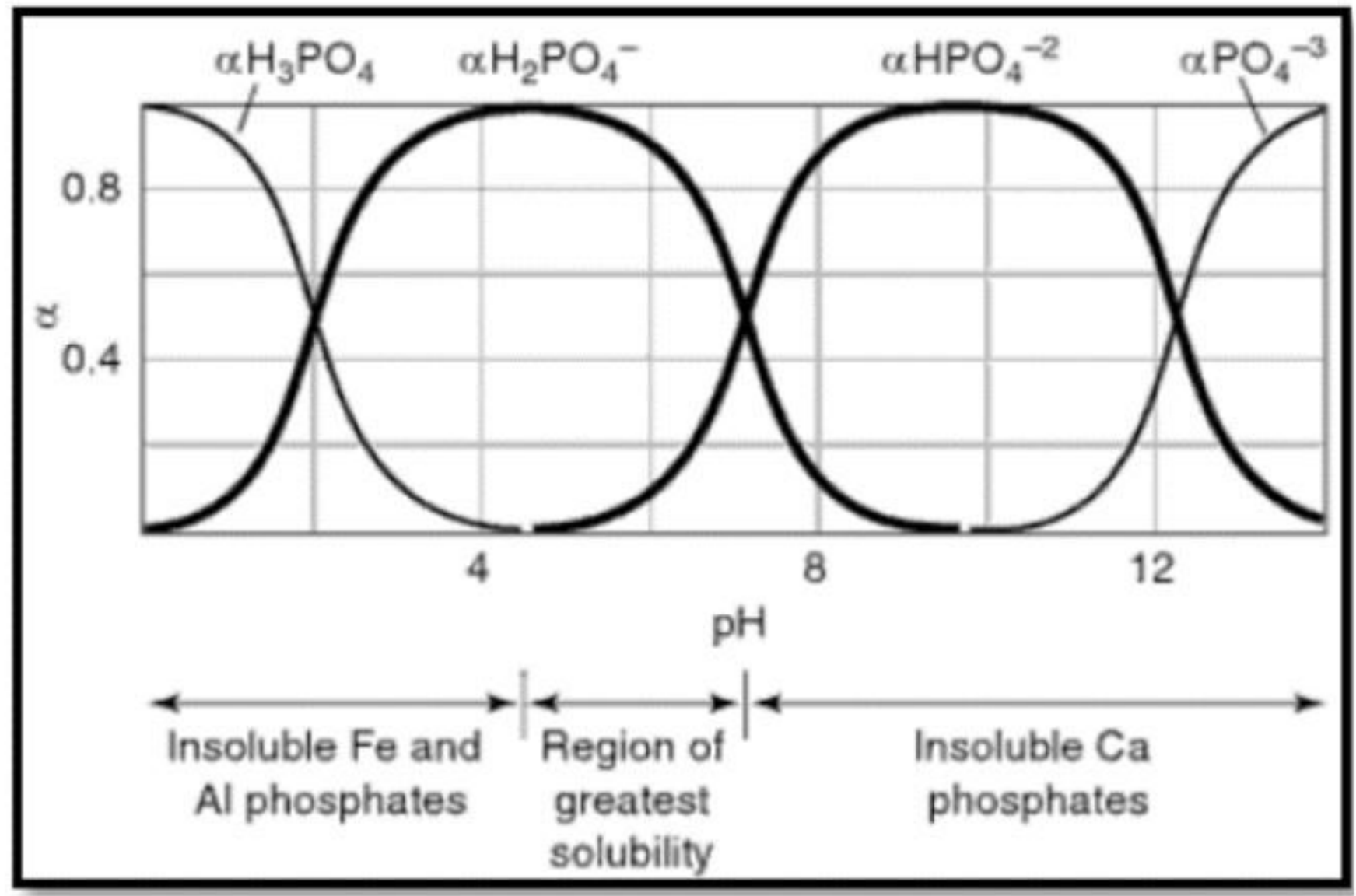

Fuente: (Guaya, 2012)

Figure 3

Species of Phosphates as a Function of $\mathrm{PH}$ 


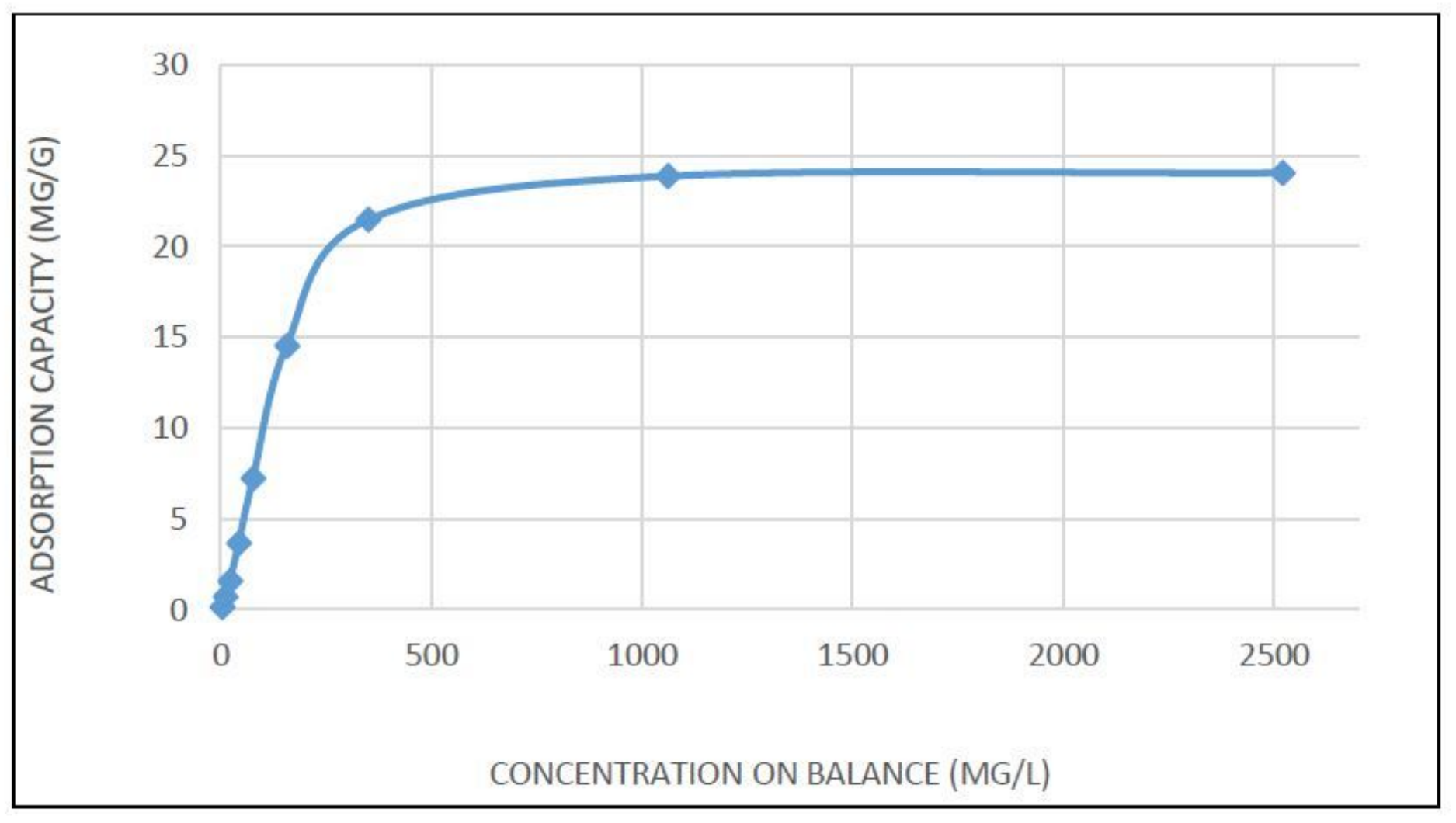

\section{Figure 4}

Experimental Isotherm of Equilibrium for Phosphate by Z-Zn

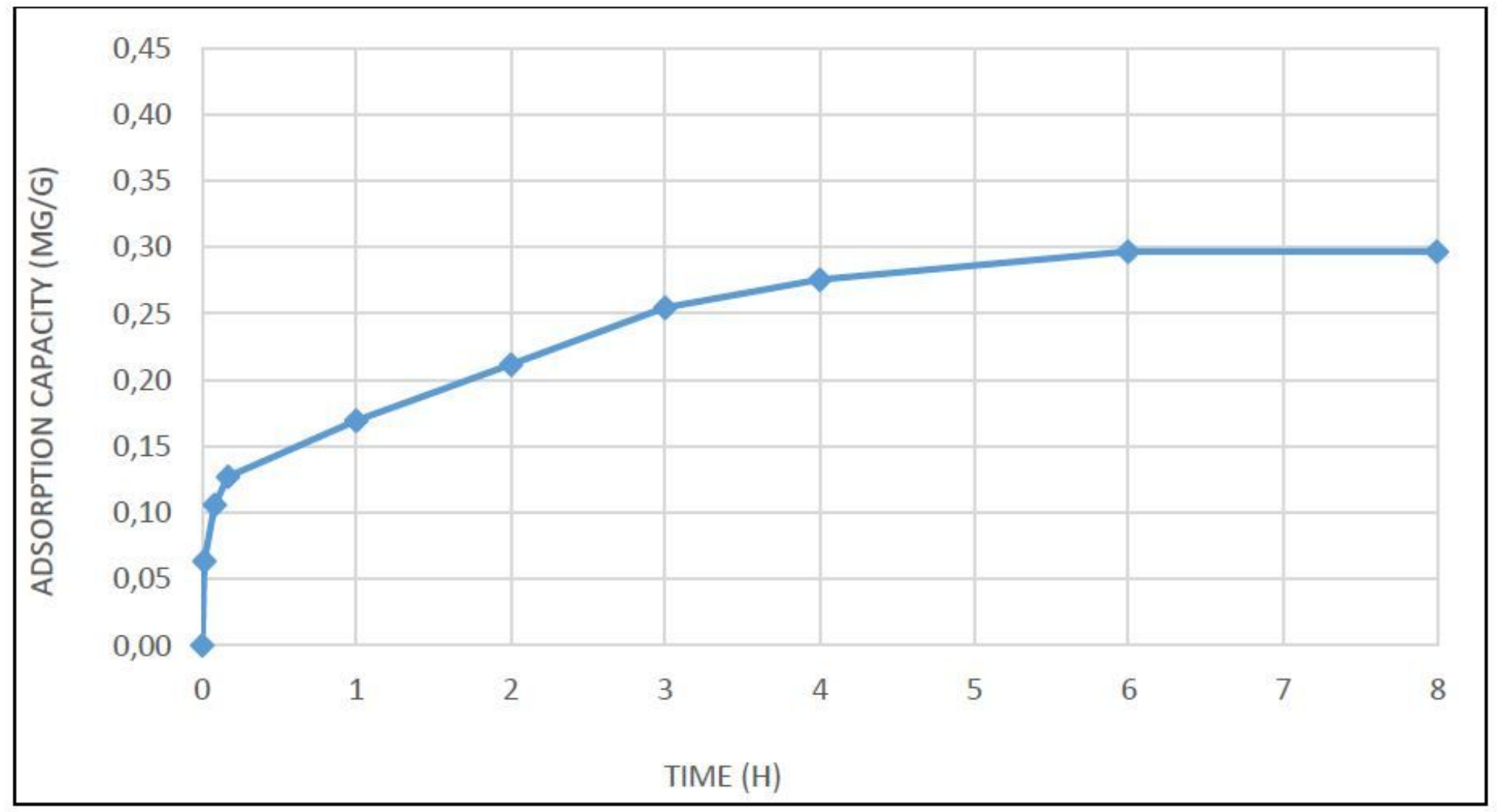

Figure 5 
Z-Zn Phosphate Kinetic Adsorption Curve

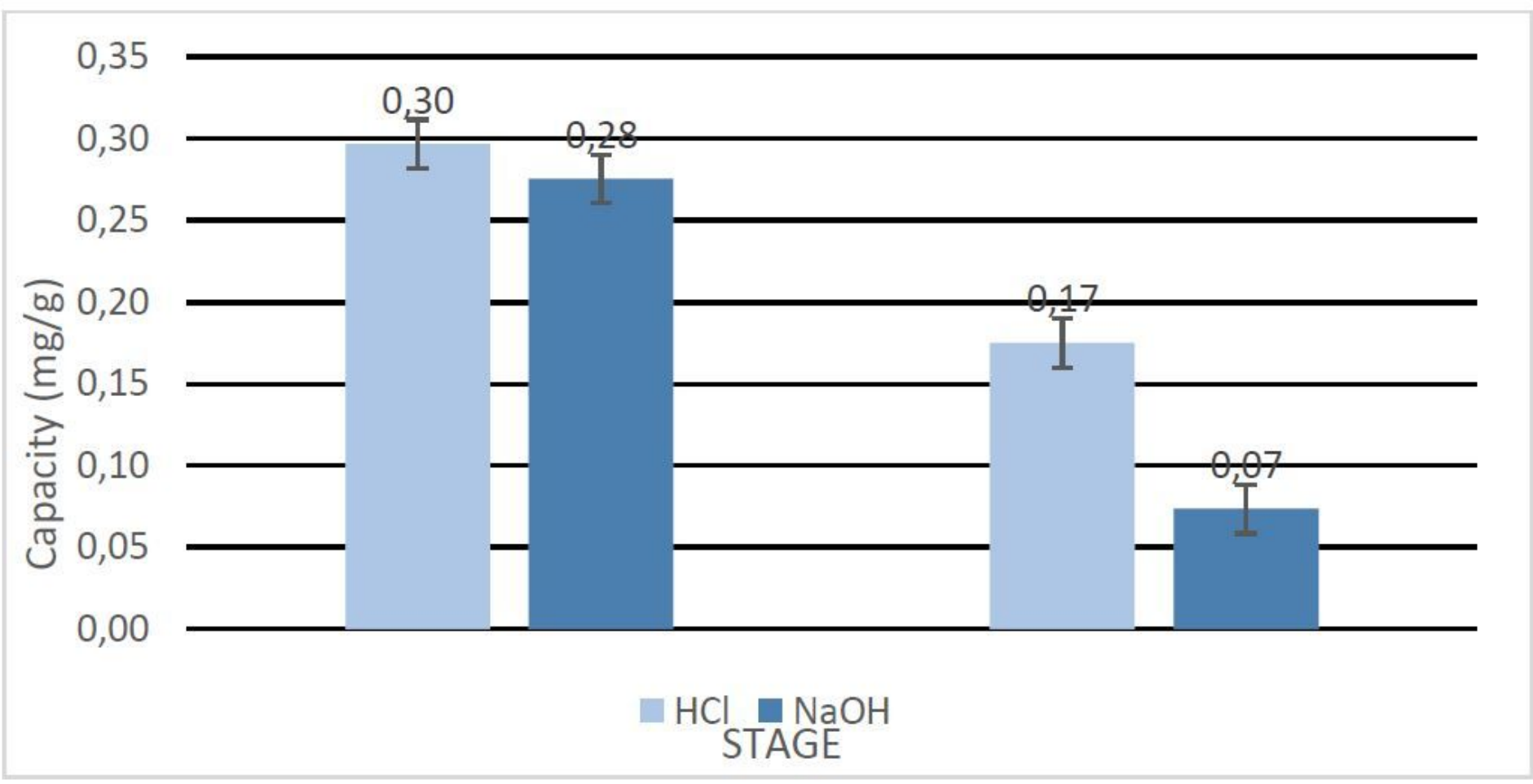

Figure 6

Representation of the Adsorption and Desorption Capacity of Phosphate in the Presence of HCL and Naoh 